Pacific Journal of Mathematics

AN ANALOGUE OF OKA'S THEOREM FOR WEAKLY

, ALdo Andretti and John VINCENT Leah Y 


\title{
AN ANALOGUE OF OKA'S THEOREM FOR WEAKLY NORMAL COMPLEX SPACES
}

\author{
William A. Adkins, Aldo Andreotti, J. V. Leahy
}

Two well known results concerning normal complex spaces are the following. First, the singular set of a normal complex space has codimension at least two. Second, this property characterizes normality for complex spaces which are local complete intersections. This second result is a theorem of Abhyankar [1] which generalizes Oka's theorem. The purpose of this paper is to prove analogues of these facts for the class of weakly normal complex spaces, which were introduced by Andreotti-Norguet [3] in a study of the space of cycles on an algebraic variety. A weakly normal complex space can have singularities in codimension one, but it will be shown that an obvious class of such singularities is generic.

1. Preliminaries. All complex spaces are assumed to be reduced. If $X$ is a complex space, there is the sheaf $\mathcal{O}_{X}$ of holomorphic functions on $X$, and the sheaf $\mathcal{O}_{X}^{c}$ of $c$-holomorphic functions on $X$. A section of $\mathcal{O}_{X}^{c}$ on an open subset $U$ of $X$ is a continuous function $f: U \rightarrow \mathbf{C}$ such that $f$ is holomorphic on the regular points of $U$. The complex space $X$ is said to be weakly normal if $\mathscr{O}_{X}=\mathscr{O}_{X}^{c}$. Examples of weakly normal spaces are normal spaces and unions of submanifolds of $\mathbf{C}^{m}$ in general position.

Let $V_{j}=\left\{\left(x_{1}, \cdots, x_{m}\right) \in \mathbf{C}^{m}: x_{k}=0\right.$ for $n \leqq k<j$ and $\left.j<k \leqq m\right\}$ where $n \leqq j \leqq m$. Then $V$, is an $n$-dimensional linear subspace of $\mathbf{C}^{m}$. Let

$$
V_{(n, m)}=\bigcup_{J=n}^{m} V_{J}=\left\{\left(x_{1}, \cdots, x_{m}\right) \in \mathbf{C}^{m}: x_{i} x_{J}=0 \text { for } n \leqq i<j \leqq m\right\}
$$

and let $S\left(V_{(n, m)}\right)$ be the singular set of $V_{(n, m)}$.

LEMMA. $\quad V_{(n, m)}$ is a weakly normal complex space and $\operatorname{dim} S\left(V_{(n, m)}\right)=$ $n-1$.

Proof. Since $\quad S\left(V_{(n, m)}\right)=\left\{\left(x_{1}, \cdots, x_{m}\right) \in \mathbf{C}^{m}: x_{n}=\cdots=x_{m}=0\right\}$, $\operatorname{dim} S\left(V_{(n, m)}\right)=n-1$. Let $f: V_{(n, m)} \rightarrow \mathbf{C}$ be a continuous function which is holomorphic on the regular points of $V_{(n, m)}$. To prove weak normality of $V_{(n, m)}$, we need to show that $f$ is holomorphic. Let $f_{j}=\left.f\right|_{v_{j}}$. By the Riemann extension theorem, $f_{j}$ is holomorphic on the $n$-plane $V$, and 
thus $f_{l}=f_{l}\left(x^{\prime}, x_{l}\right)$ is a convergent power series, where $x^{\prime}=\left(x_{1}, \cdots, x_{n-1}\right)$ and $x_{j}$ are coordinates on $V_{j}$. Since $\left.f_{j}\right|_{x_{j}=0}=\left.f_{k}\right|_{x_{k}=0}$ for $n \leqq j, k \leqq m$, we let $f_{0}\left(x^{\prime}\right)=f_{j}\left(x^{\prime}, 0\right)$ and set $g_{\jmath}\left(x^{\prime}, x_{\jmath}\right)=f_{j}\left(x^{\prime}, x_{\jmath}\right)-f_{0}\left(x^{\prime}\right)$ for $n \leqq j \leqq$ $m$. Then $f\left(x_{1}, \cdots, x_{m}\right)=f_{0}\left(x^{\prime}\right)+\sum_{l=n}^{m} g_{\jmath}\left(x^{\prime}, x_{\jmath}\right)$ and hence $f$ is holomorphic on $V_{(n, m)}$.

If $X$ is a complex space with $\operatorname{dim} X=n$, let $\operatorname{Sg}(X)=$ $S(X) \cup\left(\cup_{0 \leqq k<n} X^{(k)}\right)$ where $S(X)$ is the singular set of $X$ and $X^{(k)}$ is the analytic subset of $X$ defined by $X^{(k)}=\{x \in X: X$ has a branch of dimension $k$ at $x\}$. If $C_{4}(X, x)$ denotes the fourth Whitney tangent cone of $X$ at $x$, then Stutz [6] has shown that $W_{4}=$ $S g(X) \cap\left\{x \in X: \operatorname{dim} C_{4}(X, x)>n\right\}$ is an analytic subset of $X$ of codimension at least two.

\section{Codimension one singularities of weakly normal} spaces. Let $X$ be a complex space. A point $x \in X$ is said to be an elementary point of type $(n, m)$, for $n \leqq m$, if the germ $(X, x)$ is isomorphic to the germ $\left(V_{(n, m)}, 0\right)$. Note that if $x \in X$ is an elementary point of type $(n, m)$, then the germ $(X, x)$ is of pure dimension $n$ and the imbedding dimension of $(X, x)$ is $m$. The set of elementary points of $X$ contains the set of regular points of $X$, i.e. the elementary points of type $(n, n)$ for some $n$. In addition, it contains a particularly simple class of singular points of $X$. If $x$ is an elementary point of type $(n, m)$ with $n<m$, then $x$ is singular and $\operatorname{dim}(S(X), x)=n-1=\operatorname{dim}(X, x)-1$.

If $\operatorname{dim} X=n$, let $Y=\cup_{0 \leqq k<n} X^{(k)}$ and let $X_{1}=\overline{X \backslash Y}$. By a theorem of Remmert, $X_{1}$ is an analytic set of pure dimension $n$. Let $X_{s}$ denote the set of all elementary points of $X$ of type $(n, m)$ for some $m$ with $m \geqq n=\operatorname{dim} X$. Hence $X_{s} \subseteq X_{1}$ and $X_{s}$ contains the regular points of $X$ of maximal dimension.

THEOREM 1. Let $X$ be a weakly normal complex space. Then $A=X_{1} \backslash X_{s}$ is an analytic subset of $X_{1}$ of codimension at least 2.

Proof. Let $n=\operatorname{dim} X$. If $\operatorname{dim} S(X) \leqq n-2$ then $A=$ $X_{1} \cap S(X)$. Hence $A$ is analytic and codimension $A \geqq 2$. Now suppose that $\operatorname{dim} S(X)=n-1$. We will show that $A=$ $X_{1} \cap\left(S g(S g(X)) \cup W_{4}\right)$. Since $S g(S g(X)) \cup W_{4}$ is an analytic set of codimension at least 2 in $X$ and since $\operatorname{dim} X=\operatorname{dim} X_{1}$, this will prove the theorem.

Let $x \in X_{s}$. If $x$ is a regular point of $X$, then $x \notin S g(\operatorname{Sg}(X)) \cup$ $W_{4}$. If $x$ is an elemetary point of type $(n, m)$ where $m>n$, then $\operatorname{dim} C_{4}(X, x)=n$. Hence $x \notin W_{4}$. Moreover, $S(X)$ is a manifold of dimension $n-1$ in a neighborhood of $x$. Thus $x \notin S g(S g(X))$. Hence $X_{s} \subseteq X_{1} \backslash\left(S g(S g(X)) \cup W_{4}\right)$ and $X_{1} \cap\left(S g(S g(X)) \cup W_{4}\right) \subseteq A$.

Now suppose that $x_{0} \in X_{1} \cap S(X) \cap\left(X_{1} \backslash\left(\operatorname{Sg}(\operatorname{Sg}(X)) \cup W_{4}\right)\right)$. Thus 
$x_{0} \in \operatorname{Sg}(X) \backslash \operatorname{Sg}(\operatorname{Sg}(X))$ and $\operatorname{dim} C_{4}\left(X, x_{0}\right)=n$. Note also that the germ $\left(X, x_{0}\right)$ is of pure dimension $n$. Since the result to be proved is local, we may assume that $X \subseteq \mathbf{C}^{t}$. By Proposition 4.2 of Stutz [6], there is a neighborhood $N$ of $x_{0}$ in $X$, a polydisc $D \subseteq \mathbf{C}^{n}$, and a choice of coordinates $x_{1}, \cdots, x_{n}$ in $\mathbf{C}^{n}$ and $y_{1}, \cdots, y_{t}$ in $\mathbf{C}^{t}$ centered at $x_{0}$ with the following properties.

If $B_{0}, \cdots, B_{r}$ are the global branches of $X \cap N$, then for each $j$ $(0 \leqq j \leqq r)$ there is a holomorphic map $f_{j}: D \rightarrow B$, such that

(a) $f_{J}$ is a homeomorphism;

(b) with respect to the coordinates $x_{1}, \cdots, x_{n}, y_{1}, \cdots, y_{t}, f_{j}(0)=0$ and

$$
f_{J}(x)=\left(x_{1}, \cdots, x_{n-1}, x_{n}^{p_{i}}, f_{n+1, j}(x), \cdots, f_{t j}(x)\right)
$$

where $p_{j}$ is a positive integer for $0 \leqq j \leqq r$;

(c) $f_{l j}\left(x_{1}, \cdots, x_{n}\right)=\sum_{\nu=p_{j}}^{\infty} f_{i j}^{(\nu)}\left(x_{1}, \cdots, x_{n-1}\right) \cdot x_{n}^{\nu}$ for $n+1 \leqq i \leqq t$ and $0 \leqq j \leqq r$.

Let $g_{\mathrm{J}}: B_{j} \rightarrow D$ be the continuous inverse of $f_{\text {J }}$ and define a map $h: X \cap N \rightarrow \mathbf{C}^{n+r}$ by $\left.\pi_{j} \circ h\right|_{B_{j}}=g_{j}$ where $\pi_{j}: \mathbf{C}^{n+r} \rightarrow \mathbf{C}_{x_{1}, \cdots, x_{n-1}, x_{n+1}}$ is the natural linear projection onto the $n$-plane with coordinates $x_{1}, \cdots, x_{n-1}, x_{n+j}$, for $0 \leqq j \leqq r$. To see that the map $h$ is well defined, note first that $S(X)$ is an $n-1$ dimensional manifold in a neighborhood of $x_{0}$. Furthermore, $B, \cap B_{k} \subseteq S(X) \cap N$ for all $j, k$. But $f_{j}\left(x^{\prime}, 0\right)=$ $\left(x^{\prime}, 0, \cdots, 0\right)=f_{k}\left(x^{\prime}, 0\right)$ where $x^{\prime}=\left(x_{1}, \cdots, x_{n-1}\right)$. Therefore, if $N$ is chosen small enough, then $B_{J} \cap B_{k}=S(X) \cap N=\left\{y_{n}=\cdots=y_{t}=0\right\}$ for $0 \leqq j, k \leqq r$. For each $\left(y_{1}, \cdots, y_{t}\right) \in S(X) \cap N$, it follows that $g_{j}(y)=$ $\left(y_{1}, \cdots, y_{n-1}, 0\right)$ for $0 \leqq j \leqq r$. Thus $h$ is a well defined continuous map.

Since the jacobian matrix $\partial f_{J} / \partial x$ is given by

$$
\frac{\partial f_{i}}{\partial x}=\left[\begin{array}{ll}
I_{n-1} & 0 \\
0 & p_{j} x_{n}^{p_{n}-1} \\
* & *
\end{array}\right]
$$

$h$ is holomorphic on the regular points of $X \cap N$. Since $X$ is weakly normal and $h$ is a homeomorphism onto its image, it follows that $h$ is biholomorphic. Therefore $x_{0}$ is an elementary singularity of type $(n, n+$ $r)$. Hence $A \subseteq X_{1} \cap\left(\operatorname{Sg}(\operatorname{Sg}(X)) \cup W_{4}\right)$ and the theorem is proved.

REMARK. Let $X$ be a weakly normal complex space and suppose that $\operatorname{codim} S(X)=1$. Theorem 1 shows that there is an elementary singularity of type $(n, m)$ where $m>n$. Since such a singular point is not normal, Theorem 1 implies the well-known theorem that $\operatorname{codim} S(X) \geqq 2$ for a normal complex space $X$. 
THEOREM 2. Let $X$ be a pure dimensional local complete intersection. Then $X$ is weakly normal if and only if $\operatorname{codim} X \backslash X_{s} \geqq 2$.

Proof. Let $A=X \backslash X_{\text {s. }}$ If $X$ is weakly normal then $\operatorname{codim} A \geqq 2$ by Theorem 1 .

Conversely, suppose $\operatorname{codim} A \geqq 2$. Since $X \backslash A=X_{s}$, the germ $(X, x)$ is weakly normal for each $x \in X \backslash A$. Since $X$ is a pure dimensional local complete intersection, $p f\left(\mathcal{O}_{X, x}\right)=\operatorname{dim} X$ for each $x \in X$, where $p f=$ profondeur. From the Hartog theorem for weaḱ normality [2], we conclude that $X$ is weakly normal.

Remarks. (1) For the case of curves, the assumption of local complete intersection is not needed. A curve $X$ is weakly normal if and only if $X \backslash X_{s}=\emptyset$. An algebraic proof of this fact was given by Bombieri [5].

(2) If $X$ is a pure dimensional hypersurface in $\mathbf{C}^{n+1}$, then Theorem 2 can be proved without the use of the Hartog theorem for weak normality. This case follows from the result of Becker in [4].

(3) Let $X \subseteq \mathbf{C}^{n+1}$ be a pure dimensional hypersurface. If $X$ is weakly normal, there is another characterization of $X \backslash X_{s}$ than that which is given by the proof of Theorem 1 . This description is as follows. There is a holomorphic function $f \in \mathcal{O}\left(\mathbf{C}^{n+1}\right)$ such that $X=$ $V(f)=\left\{x \in \mathbf{C}^{n+1}: f(x)=0\right\}$ and such that there is a sheaf equality $(f) \cdot \mathscr{O}^{\prime}=\mathscr{I}_{X}$ where $\mathscr{I}_{X}$ is the sheaf of ideals of $X$. Then

$$
S(X)=\left\{x \in X: \frac{\partial f}{\partial z_{i}}(x)=0 \text { for } 1 \leqq i \leqq n+1\right\}
$$

At a point $x_{0} \in S(X)$ the Hessian form is defined by

$$
H(f)_{x_{0}}(u)=\sum_{h, j=1}^{n+1} \frac{\partial^{2} f}{\partial z_{i} \partial z_{j}}\left(x_{0}\right) \cdot u_{i} u_{j}
$$

Let $\mu\left(x_{0}\right)=\operatorname{rank} H(f)_{x_{0}}$ and set $S_{2}(X)=\{x \in S(X): \mu(x) \leqq 1\}$.

Claim. If $X$ is weakly normal and $\operatorname{dim} S(X)=n-1$, then

$$
W_{4} \cap(S(X) \backslash \operatorname{Sg}(S(X)))=S_{2} \cap(S(X) \backslash \operatorname{Sg}(S(X))) .
$$

Proof. From the proof of Theorem 1, $X \backslash X_{s}=$ $\operatorname{Sg}(S(X)) \cup W_{4}$. Suppose $x \in S(X) \backslash \operatorname{Sg}(S(X))$ but $x \notin W_{4}$. Then the proof of Theorem 1 shows that $x$ is an elementary singular point of type $(n, n+1)$. A proper choice of local coordinates about $x$ shows that $(X, x)$ is isomorphic to $\left(V\left(z_{1} z_{2}\right), 0\right)$. Hence $\mu(x)=2$ and $x \notin S_{2}(X)$. 
Now suppose that $x \in S(X) \backslash \operatorname{Sg}(S(X))$ but $x \notin S_{2}(X)$. Thus $\mu(x) \geqq 2$. If $\mu(x)>2$ then the implicit function theorem shows that $\operatorname{dim}(S(X), x) \leqq n-2$. Therefore $\mu(x)=2$ and choosing convenient local coordinates centered at $x$ gives $f(z)=a z_{1} z_{2}+0(3)$ where $a \neq 0$. Hence $x$ is an elementary singular point of type $(n, n+$ 1). Therefore, $x \notin W_{4}$ and the claim is proved.

For weakly normal hypersurfaces this claim gives an easy differential criterion for computing the portion of the set $W_{4}$ which is contained in $S(X) \backslash \operatorname{Sg}(S(X))$. This claim is false for hypersurfaces which are not weakly normal.

Example. Let $X=\left\{(x, y, z) \in \mathbf{C}^{3}: x^{2}-z y^{2}=0\right\}$ be the Cayley umbrella in $\mathbf{C}^{3}$. Then $X \backslash X_{s}=\{(0,0,0)\}$ so that $X$ is weakly normal by Theorem 2. Remark (3) then shows that $\left.W_{4}=\{0,0,0)\right\}$.

\section{REFERENCES}

1. Shreeram Abhyankar, Concepts of order and rank on a complex space and a condition for normality, Math. Annalen, 141 (1960), 171-192.

2. Aldo Andreotti and Per Holm, Parametric spaces, preprint.

3. Aldo Andreotti and Francois Norguet, La convexite holomorphe dans l'espace analytic des cycles d'une variete algebrique, Ann. Scuola Norm. Sup. Pisa, s. 3, 21 (1967), 31-82.

4. Joseph Becker, Normal Hypersurfaces, Pacific J. Math. 61 (1975), 17-19.

5. Enrico Bombieri, Seminormalite e singolarite ordinarie, Symposia Mathematica XI, Academic Press, (1973), 205-210.

6. John Stutz, Analytic sets as branched coverings, Trans. Amer. Math. Soc., 166 (1972), 241-259.

Received December 20, 1976.

InStitute for AdVANCEd Study

PRINCETON, NJ 08540

Oregon STate University

Corvallis, OR 97331

AND

UNIVERSITY OF OREGON

EUGENE, OR 97403 



\section{PACIFIC JOURNAL OF MATHEMATICS}

\section{EDITORS}

RichaRd ARENS (Managing Editor)

University of California

Los Angeles, CA 90024

\section{R. A. Beaumont}

University of Washington

Seattle, WA 98105

C. C. Moore

University of California

Berkeley, CA 94720
J. DugunduI

Department of Mathematics

University of Southern California

Los Angeles, CA 90007

R. Finn AND J. Milgram

Stanford University

Stanford, CA 94305

\section{ASSOCIATE EDITORS}
E. F. BECKENBACH
B. H. NeumanN
F. WOLF
K. YoshidA

\section{SUPPORTING INSTITUTIONS}

UNIVERSITY OF BRITISH COLUMBIA

CALIFORNIA INSTITUTE OF TECHNOLOGY

UNIVERSITY OF CALIFORNIA

MONTANA STATE UNIVERSITY

UNIVERSITY OF NEVADA

NEW MEXICO STATE UNIVERSITY

OREGON STATE UNIVERSITY

UNIVERSITY OF OREGON

OSAKA UNIVERSITY

\author{
UNIVERSITY OF SOUTHERN CALIFORNIA \\ STANFORD UNIVERSITY \\ UNIVERSITY OF HAWAII \\ UNIVERSITY OF TOKYO \\ UNIVERSITY OF UTAH \\ WASHINGTON STATE UNIVERSITY \\ UNIVERSITY OF WASHINGTON \\ AMERICAN MATHEMATICAL SOCIETY
}

The Supporting Institutions listed above contribute to the cost of publication of this Journal, but they are not owners or publishers and have no responsibility for its contents or policies.

Mathematical papers intended for publication in the Pacific Journal of Mathematics should be in typed form or offset-reproduced (not dittoed), double spaced with large margins. Underline Greek letters in red, German in green, and script in blue. The first paragraph or two must be capable of being used separately as a synopsis of the entire paper. Items of the bibliography should not be cited there unless absolutely necessary, in which case they must be identified by author and Journal, rather than by item number. Manuscripts, in duplicate, may be sent to any one of the four editors. Please classify according to the scheme of Math. Reviews, Index to Vol. 39. All other communications should be addressed to the managing editor, or Elaine Barth, University of California, Los Angeles, California, 90024.

100 reprints are provided free for each article, only if page charges have been substantially paid. Additional copies may be obtained at cost in multiples of 50 .

The Pacific Journal of Mathematics is issued monthly as of January 1966. Regular subscription rate: $\$ 72.00$ a year (6 Vols., 12 issues). Special rate: $\$ 36.00$ a year to individual members of supporting institutions.

Subscriptions, orders for back numbers, and changes of address should be sent to Pacific Journal of Mathematics, 103 Highland Boulevard, Berkeley, California, 94708.

PUBLISHED BY PACIFIC JOURNAL OF MATHEMATICS, A NON-PROFIT CORPORATION

Printed at Jerusalem Academic Press, POB 2390, Jerusalem, Israel. 


\section{Pacific Journal of Mathematics}

Vol. 68, No. 2

April, 1977

William Allen Adkins, Aldo Andreotti and John Vincent Leahy, An analogue of Oka's theorem for weakly normal complex spaces ........

Ann K. Boyle, M. G. Deshpande and Edmund H. Feller, On nonsingularly

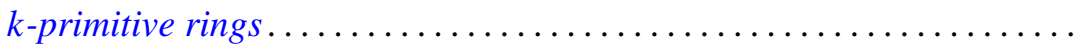

Rolando Basim Chuaqui, Measures invariant under a group of

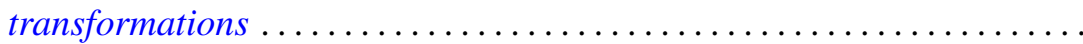

Wendell Dan Curtis and Forrest Miller, Gauge groups and classification of bundles with simple structural group .......................

Garret J. Etgen and Willie Taylor, The essential uniqueness of bounded nonoscillatory solutions of certain even order differential equations

Paul Ezust, On a representation theory for ideal systems

Richard Carl Gilbert, The deficiency index of a third order operator ........

John Norman Ginsburg, $S$-spaces in countably compact spaces using Ostaszewski's method.

Basil Gordon and S. P. Mohanty, On a theorem of Delaunay and some

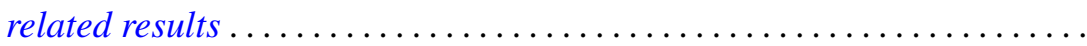

Douglas Lloyd Grant, Topological groups which satisfy an open mapping

theorem.

Charles Lemuel Hagopian, A characterization of solenoids

Kyong Taik Hahn, On completeness of the Bergman metric and its

subordinate metrics. II .

G. Hochschild and David Wheeler Wigner, Abstractly split group extensions.

Gary S. Itzkowitz, Inner invariant subspaces ...............

Jiang Luh and Mohan S. Putcha, A commutativity theorem for

non-associative algebras over a principal ideal domain.

Donald J. Newman and A. R. Reddy, Addendum to: "Rational approximation of $e^{-x}$ on the positive real axis".....

Akio Osada, On the distribution of a-points of a strongly annular function ....

Jeffrey Lynn Spielman, A characterization of the Gaussian distribution in a Hilbert space. .

Robert Moffatt Stephenson Jr., Symmetrizable-closed spaces ...

Peter George Trotter and Takayuki Tamura, Completely semisimple inverse $\Delta$-semigroups admitting principal series . . . . . . . .

Charles Irvin Vinsonhaler and William Jennings Wickless, Torsion free abelian groups quasi-projective over their endomorphism rings...

Frank Arvey Wattenberg, Topologies on the set of closed subsets ... 